\title{
IPTEKS PENERBITAN SURAT PERMINTAAN PENJELASAN ATAS DATA DAN ATAU KETERANGAN (SP2DK) OLEH ACCOUNT REPRESENTATIVE DI KANTOR PELAYANAN PAJAK PRATAMA MANADO
}

\author{
Viva A. A. Kowel ${ }^{1}$, Thessa F. Y. Sondakh ${ }^{2}$, Ailling I. Pua ${ }^{3}$, Novi S. Budiarso ${ }^{4}$ \\ 1,2,3,4 Jurusan Akuntansi, Fakultas Ekonomi dan Bisnis Universitas Sam Ratulangi, Jl. Kampus Unsrat, Manado, \\ 95115, Indonesia \\ Email : vivakowel@gmail.com
}

\begin{abstract}
Tax has great contribution on the development in Indonesia. Therefore, the supervision for tax obligation fulfillment is a must. In fulfilling their tax obligation, taxpayers are supervised by Account Representative to ensure they are obedient in paying taxes. One way for Account Representative to supervise taxpayers is by issuing SP2DK. Account Representative will conduct analysis on taxpayer's data and clarification. The authority expects that an effective issuance of SP2DK will increase the tax revenue of KPP Pratama Manado. Unfortunately, in its practice there are still factors that obstruct the issuance process of SP2DK and the tax revenue realization after $S P 2 D K$ is issued. Due to these facts, Account Representative is required to have good knowledge and skill in analyzing and comparing the data from taxpayer to maximize tax revenue from SP2DK issuance.
\end{abstract}

Keywords : SP2DK, Account Representative, analysis, income, maximization

\section{PENDAHULUAN}

Penerimaan dari sektor pajak memiliki kontribusi besar terhadap penerimaan kas Negara, sehingga jumlah penerimaan yang sudah ditargetkan perlu dioptimalkan. Menurut Mardiasmo (2016), pajak memiliki fungsi budgetair karena pembiayaan pengeluaran di bidang pemerintahan maupun pembangunan bersumber dari pajak. Menurut informasi APBN 2018, pendapatan negara ditargetkan sebesar Rp1.894,7 triliun. Dari total target penerimaan, 85\% diantaranya berasal dari penerimaan perpajakan, yaitu sebesar Rp1.618,1 triliun.

Penerimaan pajak bergantung pada kesediaan Wajib Pajak untuk membayar pajak terutang sesuai dengan peraturan perpajakan yang berlaku di Indonesia. Menurut Toyyibatuz Zaimah (2016), akibat dari penerapan self assessment system di Indonesia, petugas pajak hanya sebatas mengawasi. Oleh karena itu, Direktorat Jenderal Pajak mengoptimalkan fungsi pengawasan melalui penggalian potensi pajak. Penggalian potensi pajak dilakukan oleh Account Representative (AR) dengan menganalisa data-data Wajib Pajak. Ketika ditemukan adanya kemungkinan belum terpenuhinya kewajiban perpajakan, akan dilakukan penerbitan Surat Permintaan Penjelasan atas Data dan/atau Keterangan (SP2DK) kepada Wajib Pajak yang bersangkutan. Menurut penelitian dari Fergie V. Parmono (2016), penerbitan SP2DK yang efektif dapat meningkatkan penerimaan perpajakan, karena realisasi penerimaan setelah SP2DK diterbitkan akan membantu pencapaian target baik dari Account Representative, Seksi Pengawasan dan Konsultasi, maupun pencapaian target dari KPP Pratama Manado.

\section{TINJAUAN PUSTAKA}

Pengertian Surat Permintaan Penjelasan atas Data dan/atau Keterangan. Surat Permintaan Penjelasan atas Data dan/atau Keterangan (SP2DK) adalah surat yang diterbitkan oleh Kepala Kantor Pelayanan Pajak sebagai tindakan untuk mengawasi Wajib Pajak lewat Account Representative dan untuk mengkonfirmasi kemungkinan bahwa Wajib Pajak belum memenuhi kewajiban perpajakan. SP2DK diterbitkan sebagai bentuk pengawasan terhadap 
penerapan self assessment system, dimana petugas pajak hanya bersifat mengawasi dan Wajib Pajak sendiri yang melakukan kewajiban perpajakannya. Menurut Hasbi Rifqiansyah, Muhammad Saifi dan Devi F. Azizah (2014), ketika pemerintah memberikan kepercayaan kepada Wajib Pajak melalui sistem self assessment ini, seharusnya pelaksanaanya dapat berjalan sesuai rencana sehingga penerimaan perpajakan tetap optimal, namun ada kalanya Wajib Pajak lalai dalam melaksanakan kewajibannya. Oleh karena itu, Account Representative melakukan fungsi pengawasan. Dalam penelitannya, E. Kusmanasari Subagiyo, Sri Mangesti Rahayu dan Amirudin Jauhari (2014) menyampaikan bahwa fungsi pengawasan dilakukan agar Wajib Pajak dapat menjalankan kewajiban perpajakan sebagaimana mestinya. Account Representative memberikan sarana dan kemudahan bagi Wajib Pajak untuk memahami bagaimana seharusnya kewajiban perpajakan dilaksanakan dengan benar. Ketika ditemukan kecenderungan bahwa Wajib Pajak tidak melaksanakan kewajiban sesuai peraturan perundang-undangan, maka SP2DK diterbitkan.

Proses Permintaan Penjelasan Data Dan Atau Keterangan Kepada Wajib Pajak. Peraturan yang menjadi dasar penerbitan SP2DK, yaitu Surat Edaran Direktur Jenderal Pajak Nomor: SE-39/PJ/2015 tentang Pengawasan Wajib Pajak Dalam Bentuk Permintaan Penjelasan Atas Data dan/atau Keterangan, Dan Kunjungan (Visit) Kepada Wajib Pajak dan Peraturan Direktur Jenderal Pajak Nomor : PER-22/PJ/2015 tentang Pencabutan Peraturan Direktorat Jenderal Pajak No. PER-170/PJ/2007 tentang Tata Cara Pelaksanaan Konseling terhadap Wajib Pajak sebagai Tindak Lanjut Surat Himbauan. Peraturan ini mengatur tentang hal-hal yang harus dilakukan saat proses permintaan penjelasan data dan atau keterangan kepada Wajib Pajak dan alternatif keputusan yang nantinya akan diambil oleh Account Representative. Dalam memaksimalkan penerimaan dan pengawasan pajak secara efektif, terintegrasi serta berkesimbungan maka Dirjen Pajak melakukan inovasi dalam sistem perpajakan dengan Aplikasi Profil Berbasis Web (Approweb) yang pengaturannya sesuai Surat Edaran Dirjen Pajak Nomor: SE-01/PJ/2012 tentang Penyempurnaan Aplikasi Approweb Sebagai Sarana Pembuatan dan Pemutakhiran Profil Wajib Pajak. Penggunaan Aplikasi Approweb sangat membantu Account Representative karena Approweb menyediakan data mengenai Wajib Pajak. Data-data yang tersedia terintegrasi dalam satu sistem, sehingga memudahkan pemantauan terhadap Wajib Pajak. Menurut Surat Edaran Dirjen Pajak Nomor: SE-39/PJ/2015, proses penerbitan SP2DK terdiri dari beberapa tahap, yaitu : persiapan, tanggapan wajib pajak, analisis terhadap tanggapan wajib pajak, tindak lanjut, dan pengadministrasian.

\section{METODE DAN TEKNIK PENERAPAN IPTEKS}

\subsection{Metode Penerapan Ipteks}

Metode Ipteks yang digunakan adalah mengimplementasikan prosedur penerbitan

Surat Permintaan Penjelasan atas Data dan atau Keterangan sesuai dengan Standard Operating Procedure melalui aplikasi Approweb di Kantor Pelayanan Pajak Pratama Manado.

\subsection{Teknik Penerapan Ipteks}

Teknik Ipteks yang diterapkan adalah melakukan pengamatan dan turut membantu proses penerapan prosedur penerbitan SP2DK sesuai Standard operating Procedure yang berlaku di Kantor Pelayanan Pajak Pratama Manado, yang terdiri dari tahap-tahap yaitu : Account Representative melakukan identifikasi awal dari data Wajib Pajak, ketika ditemukan data yang harus diklarifikasi maka Account Representative menerbitkan SP2DK menggunakan aplikasi Approweb. Selanjutnya, SP2DK disampaikan kepada Wajib Pajak. Setelah itu, Account Representative menganalisis tanggapan dari Wajib Pajak Selanjutnya Account Representative menentukan tindak lanjut apa yan sesuai terhadap tanggapan Wajib Pajak dan data yang terdapat pada Account Representative. Terakhir adalah 
pengadministrasian kegiatan permintaan penjelasan, dengan merekam tindak lanjut serta saran dan rekomendasi dari Account Representative terhadap Wajib Pajak.

\section{PEMBAHASAN}

\subsection{Gambaran Objek Penerapan Ipteks}

Kantor Pelayanan Pajak Pratama Manado merupakan instansi pemerintah yang berada di Kota Manado, yang merupakan unit kerja dari Direktorat Jenderal Pajak. KPP Pratama Manado berada dalam lingkup wilayah kerja Kantor Wilayah DJP Sulawesi Utara, Tengah, Gorontalo, dan Maluku Utara. Wilayah kerja untuk Manado terdiri dari 11 kecamatan, dan di kota Tomohon mencakup 5 kecamatan. Jumlah Wajib Pajak yang terdaftar hingga saat ini 185.581. KPP Pratama Manado bertugas untuk melaksanakan kegiatan pelayanan di bidang perpajakan. KPP Pratama Manado menghimpun penerimaan negara dari dengan melakukan usaha-usaha untuk memaksimalkan penerimaan di sektor perpajakan (Wikipedia, 2010).

\subsection{Pembahasan}

Penerbitan SP2DK mengacu pada Surat Edaran Direktur Jenderal Pajak No: SE39/PJ/2015. Prosedur penerbitan SP2DK yang diterapkan di Kantor Pelayanan Pajak Pratama Manado, yaitu :

1. Persiapan

Dalam penerapan di KPP Pratama Manado, tahapan persiapan terdiri dari 3 kegiatan utama, yaitu :

- Identifikasi data awal oleh Account Representative

Account Representative melakukan analisis awal terhadap profil Wajib Pajak yang telah tersedia dalam sistem informasi kemudian membandingkan dengan data-data yang ada. Ketika analisis dilakukan oleh Account Representative dan ditemukan adanya data yang perlu diklarifikasi berhubungan dengan kewajiban perpajakan dari Wajib Pajak, maka SP2DK diterbitkan.

- Penerbitan dokumen SP2DK

SP2DK diterbitkan oleh Kepala Kantor atas dasar analisis dari Account Representative yang bertanggung jawab untuk pengawasan dari Wajib Pajak yang bersangkutan. Kegiatan analisis dan penerbitan dokumen SP2DK dilakukan melalui aplikasi Approweb. Penggunaan Approweb untuk kegiatan pengawasan Wajib Pajak telah dituangkan dalam Lampiran Surat Edaran Direktur Jenderal Pajak Nomor : SE-49/PJ/2016 tentang Pengawasan Wajib Pajak melalui Sistem Informasi. Penggunaan Approweb sebagai alat bantu untuk melakukan pengawasan terhadap Wajib Pajak, sangat membantu para Account Representative karena di dalamnya mempermudah analisis data sampai pada penerbitan SP2DK. Account Representative melakukan analisis data Wajib Pajak melalui sistem informasi, kemudian data-data yang perlu diklarifikasi akan diproses melalui Aprroweb untuk menerbitkan dokumen SP2DK.

- Penyampaian dokumen SP2DK kepada Wajib Pajak

Di KPP Pratama Manado, sebagian besar SP2DK disampaikan kepada Wajib Pajak melalui pos, kecuali ada pertimbangan khusus dari Account Representative sehingga SP2DK disampaikan langsung melalui kegiatan visit kepada Wajib pajak. Hambatan yang sering ditemui pada tahap persiapan dan penyampaian SP2DK adalah ketika terjadi gangguan berhubungan operasi dari aplikasi Approweb yang menghambat kegiatan pengawasan dari Account Representative. Tahap ini juga mengalami kesulitan jika Wajib Pajak tidak memiliki data-data yang diperlukan oleh Account Representative, termasuk jika Wajib Pajak tidak memberikan informasi mengenai alamat yang benar, karena baik dokumen SP2DK dikirim melalui kurir maupun oleh Account Representative secara 
langsung, alamat Wajib Pajak akan sulit untuk dilacak. Untuk mengatasi hambatan berhubungan dengan kegiatan persiapan dan penyampaian SP2DK, maka Account Representative harus lebih teliti dalam melakukan kegiatan analisis data, dan menggali data-data melalui sistem informasi yang tersedia di KPP Pratama Pratama Manado, salah satunya dengan memaksimalkan penggunaan Sistem Informasi Direktorat Jenderal Pajak (SIDJP) dan Approweb. Sistem informasi yang tersedia sangat membantu dalam proses analisis data Wajib Pajak.

2. Tanggapan Wajib Pajak

Setelah Wajib Pajak menerima dokumen SP2DK, maka Wajib Pajak melakukan klarifikasi atas data-data atau keterangan yang disampaikan dalam SP2DK. Menurut Nurul Fadlina Mustamin (2016), penyampaian tanggapan dapat dilakukan dengan dua cara, yaitu secara langsung maupun tertulis. Jawaban secara langsung diberikan oleh Wajib Pajak dengan melakukan kunjungan ke kantor Pelayanan Pajak Pratama Manado dan bertemu langsung dengan Account Representative yang mengirimkan dokumen SP2DK. Wajib Pajak lalu menjelaskan dengan lisan tentang hal-hal yang dipertanyakan oleh Account Representative. Cara kedua yaitu dengan memberikan tanggapan secara tertulis, yaitu Wajib Pajak mengirimkan surat balasan ke KPP Pratama Manado. Namun dalam prakteknya, ada keadaan dimana Wajib Pajak tidak memberikan tanggapan dan SP2DK yang dikirimkan kembali pos (Kempos). SP2DK Kempos kemudian dibagikan kembali kepada AR yang bertanggung jawab atas Wajib Pajak bersangkutan. Selanjutnya AR menentukan tindak lanjut paling tepat untuk keadaan tersebut.

3. Analisis atas Tanggapan Wajib Pajak

Analisis dilakukan oleh Account Representative dengan membandingkan tanggapan dari Wajib Pajak dengan data pendukung yang dimiliki oleh Account Representative. Hambatan yang sering ditemui dalam tahap ini, yaitu ketidakcocokan antara data yang ditemui Account Representative dan tanggapan atau klarifikasi dari Wajib Pajak. Ketika terjadi ketidakcocokan, maka Account Representative akan melakukan analisis dari data tersebut dan mencari data-data yang memiliki hubungan dengan hal yang menjadi poin klarifikasi. Account Representative melakukan analisis lebih dalam dan melakukan pencarian data melalui sistem informasi. Cara lain yang ditempuh yaitu dengan melakukan visit kepada Wajib Pajak untuk menjelaskan secara langsung bagian-bagian yang perlu untuk ditegaskan kepada Wajib Pajak. Dengan melakukan visit, maka Account Representative dapat menjelaskan secara rinci dan mengetahui hambatan dari Wajib Pajak dalam pemenuhan kewajiban perpajakan.

4. Tindak Lanjut

Tindak lanjut diambil sesuai dengan tanggapan dari Wajib Pajak dan hasil analisis Account Representative. Apabila Wajib Pajak memberikan jawaban berupa sanggahan, namun sanggahan tersebut sesuai dengan hasil analisis dari Account Representative, maka kasus akan ditutup dan dianggap selesai. Berdasarkan Peraturan Dirjen Pajak Nomor: PER-22/PJ/2015, apabila telah lewat 14 hari dari jangka waktu surat himbauan untuk memperoleh kesimpulan dari data klarifikasi oleh Wajib Pajak, maka dilakukan konseling. Hasil keputusan untuk tindak lanjut maupun rekomendasi dari AR dituangkan melalui LHP2DK dan direkam di Approweb.

5. Pengadministrasian

Kegiatan pengadministrasian merupakan tahap akhir dari prosedur permintaan penjelasan atas data dan/atau keterangan. Account Representative setelah memutuskan tindak lanjut apa yang sesuai dengan tanggapan Wajib pajak dan analisis dari Account Representative, maka kasus akan ditutup oleh Account Representative sesuai dengan kebijakan dari Account Representative. Kegiatan ini diakhiri dengan pembuatan 
dokumen LHP2DK yang merekam hasil dari permintaan penjelasan serta kesimpulan dan rekomendasi tindakan apa yang diambil.

\section{KESIMPULAN DAN SARAN}

\subsection{Kesimpulan}

Dalam proses permintaan perjelasan atas data dan atau keterangan di KPP Pratama Manado, ditemui adanya hambatan baik yang berasal dari sistem, dan aplikasi yang digunakan oleh Account Representative, maupun hambatan yang berasal dari Wajib Pajak yang menyebabkan terhambatnya proses analisis data. Namun secara keseluruhan penerbitan SP2DK oleh Account Representative kepada Wajib Pajak yang dilakukan di KPP Pratama Manado sudah dilakukan sesuai prosedur yang ditetapkan dalam peraturan perundangundangan, hanya saja jika ada perubahan bukan hal yang mendasar, tergantung pengaturan dan kreativitas dari masing-masing Account Representative. Penerapan prosedur sesuai peraturan akan membantu para petugas pajak untuk mengambil tindakan yang tepat atas kegiatan pengawasan Wajib Pajak, sehingga dapat memaksimalkan realisasi penerimaan setelah penerbitan SP2DK. Selain itu, penggunaan sistem informasi yang terintegrasi sangat membantu proses penerbitan SP2DK baik dari tahan persiapan sampai pada pengadministrasian. Penggunaan SIDJP dan Approweb membantu Account Representative dalam proses analisa data untuk menentukan tindak lanjut yang paling sesuai untuk Wajib Pajak.

\subsection{Saran}

Untuk mengatasi hambatan-hambatan baik dalam proses pembuatan dan penyampaian SP2DK, maupun dalam realisasi penerimaan setelah diterbitkannya SP2DK, Account Representative perlu meningkatkan pengetahuan, keahlian dan sikap profesional. Semua hal itu diperlukan saat menganalisis kebenaran data, menyimpulkan sampai pada tindak lanjut dari hasil klarifikasi kepada Wajib Pajak agar AR tidak keliru dalam mengambil tindakan bagi Wajib Pajak. Tindak lanjut yang tepat akan memaksimalkan realisasi penerimaan setelah SP2DK diterbitkan, sehingga tujuan sesungguhnya dari penerbitan SP2DK yaitu untuk membantu meningkatkan penerimaan di sektor pajak akan tercapai. Selain itu, sistem informasi yang sudah terintegrasi di KPP Pratama Manado hendaknya diperlihara dan ditingkatkan, karena sangat berpengaruh terhadap kegiatan analisis dan pengawasan terhadap Wajib Pajak. Sistem informasi yang ada baik SIDJP maupun Approweb sangat membantu dalam proses identifikasi awal maupun analisis data Wajib Pajak. Ketika pengetahuan dan keahlian Account Representative untuk menganalisis data dipadukan dengan sistem informasi yang memadai, maka proses penggalian potensi umumnya, maupun realisasi penerimaan setelah penerbitan SP2DK akan memperoleh hasil yang efektif.

\section{DAFTAR PUSTAKA}

Direktorat Jenderal Pajak. 2012. Surat Edaran Nomor SE-01/PJ/2012 Penyempurnaan Aplikasi Approweb Sebagai Sarana Pembuatan dan Pemutakhiran Profil Wajib Pajak. Jakarta

Direktorat Jenderal Pajak. 2015. Peraturan Direktur Jenderal Pajak Nomor PER-22/PJ/2015. Jakarta.

Direktorat Jenderal Pajak. 2015. Surat Edaran Direktur Jenderal Pajak Nomor SE-39/PJ/2015 Pengawasan Wajib Pajak Dalam Bentuk Permintaan Penjelasan Atas Data dan/atau Keterangan, Dan Kunjungan (Visit) Kepada Wajib Pajak. Jakarta.

Direktorat Jenderal Pajak. 2016. Lampiran Surat Edaran Direktur Jenderal Pajak Nomor SE-49/PJ/2016 Pengawasan Wajib Melalui Sistem Informasi. Jakarta. 
Kementerian Keuangan Indonesia (2017). Informasi APBN 2018. Jakarta.

Mardiasmo, 2016. Perpajakan, Penerbit Andi: Yogyakarta.

Mustamin, Nurul Fadlina, 2016. Surat Permintaan Penjelasan Data dan/atau Keterangan, (Online), (https://prezi.com/9vf8g4jujcyk/surat-permintaan-penjelasan-datadanatau-keterangan/, diakses 8 November 2018)

Parmono, Fergie Veronica, 2016. Analisis Efektivitas Surat Himbauan Atau Surat Permintaan Penjelasan Atas Data Atau Keterangan (SP2DK) Terhadap Penerimaan Pajak Pada KPP Pratama Manado. Vol.4 No.1. Universitas Sam Ratulangi. Manado. Hal. 934-944.

Rifqiansyah, Hasbi, Muhammad Saifi dan Devi F. Azizah. 2014. Analisis Efektivitas Dan Kontribusi Penagihan Pajak Aktif Terhadap Pencairan Tunggakan Pajak (Studi Pada Kantor Pelayanan Pajak Pratama Malang Utara), Jurnal Administrasi Bisnis (JAB), Vol.15 No.1

Subagiyo, E. Kusmanasari, Sri M. Rahayu dan Amirudin Jauhari, 2014. Analisis FaktorFaktor yang Mempengaruhi Wajib Pajak dalam Merespon Surat Himbauan terhadap Kepatuhan Penyampaian Surat Himbauan SPT Tahunan (Studi pada Kantor Pelayanan Pajak Pratama Batu), Fakultas Ilmu Administrasi. Universitas Brawijaya. Malang. Vol.3 No.1

Wikipedia, 2010. Kantor Pelayanan Pajak. (https://id.wikipedia.org, diakses 13 November 2018).

Zaimah, Toyyibatuz. 2016. Efektivitas Sistem Self Assessment Dalam Pajak Penghasilan di Kantor Pelayanan Pajak Pratama Batu (Perspektif Hukum Positif dan Hukum Islam). Fakultas Syariah UIN Maulana Malik Ibrahim Malang). Malang. Vol.7 No.1. Hal. 44-58 